\title{
Artigos da revista Medicina (Ribeirão Preto) agora com Digital Object Identifier -DOI.
}

\section{Articles of the journal Medicine (Ribeirão Preto) now with Digital Object Identifier -DOI.}

Orlando de Castro e Silva ${ }^{1}$, Marlene Candida de Faria ${ }^{2}$

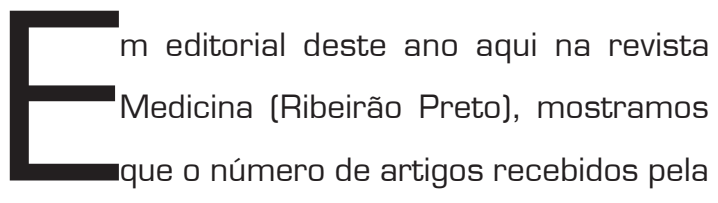

nossa revista aumentou de forma exponencial a partir de 2011. ${ }^{1}$ Isto ocorreu como consequência, sobretudo, da regularização da periodicidade da revista e como corolário o reconhecimento pela CAPES, atribuindo a ela o conceito B2 e o valor de 20 pontos para os autores, para cada trabalho publicado, como crédito junto a essa agência de fomento, avaliadora dos programas de pós-graduação do Brasil. A demanda cresceu e tornou-se necessária sua publicação bimensal, a partir de 2015, para manter o nível de periodicidade e a excelência da revista. ${ }^{1}$

Com estas medidas a visibilidade da revista cresceu. Já há artigos para compor a revista em todo ano de 2015. E esta era nossa meta, buscar indexadores mais universais e continuar atrair, cada vez mais, os autores para nela publicarem seus resultados.
Assim, em junho deste ano, recebemos e-mail da Seção de Apoio ao Credenciamento de Revistas USP, Departamento Técnico do Sistema Integrado de Bibliotecas - DT/SIBi,Universidade de São Paulo http://www. bibliotecas.usp.br², que transcrevo abaixo:

\section{SIBi/DT/SACR/OF.EXT.2102/2014}

Prezado editor,

O Sistema Integrado de Bibliotecas - SIBi, por meio de seu Programa de Apoio às Publicações Científicas Periódicas da USP, vem consolidando diversas ações que corroborem com o aperfeiçoamento, profissionalização, visibilidade a acessibilidade das revistas cientificas editadas oficialmente pela USP.

No início de 2013 a Universidade de São Paulo filiou-se à CrossRef e com isto viabilizou-se a atribuição de nomes DOI (Digital Object Identifier) aos periódicos editados oficialmente pela USP.

\footnotetext{
1. Editor-chefe, Revista Medicina. Prof.Titular do Departamento de Cirurgia e Anatomia da Faculdade de Medicina de Ribeirão Preto, Universidade de São Paulo (FMRP-USP).

2. Secretaria, Revista Medicina.
} 
Sendo assim, informamos que foram atribuídos nomes DOI para os artigos da revista Medicina (Ribeirão Pretol disponiveis no Portal de Revistas da USP (http://www.revistas.usp.br/rmrp].

Agradecemos por divulgar junto aos autores dos artigos a adoção do DOI pela revista Medicina (Ribeirão Pretol para atualização desta informação na Plataforma Lattes e outras bases de dados.

Atenciosamente,

Seção de Apoio ao Credenciamento de Revistas USP Departamento Técnico do Sistema Integrado de Bibliotecas - DT/SIBi - Universidade de São Paulo http://www.bibliotecas.usp.br

Desta forma, foram tomadas as providências necessárias para o cumprir o planejamento para publicação dos próximos fascículos da revista Medicina (Ribeirão Preto) incluindo uma etapa de atribuição de nomes DOI, para garantirmos a pontualidade da publicação e a qualidade dos metadados. Deliberamos que a partir de agora nenhuma alteração poderá ser feita nos metadados dos artigos publicados na revista sem que haja uma comunicação harmoniosa entre a equipe editorial e o Departamento Técnico do SIBiUSP, que é o Sistema Integrado de Bibliotecas da Universidade de São Paulo, que oferece prioritariamente suporte às atividades de ensino, pesquisa e extensão de docentes, pesquisadores e alunos de graduação e pós-graduação da USP. O SIBiUSP integra 43 bibliotecas de faculdades distribuídas em seis campi universitários, com acervo total de mais de 6 milhões de volumes. Tal conduta justifica-se pela garantia de que os metadados depositados no sistema da CrossRef sejam fidedignos aos que estão publicados no Portal de Revistas da USP. $3,4,5$

\section{Explicações necessárias}

DOI significa Digital Object Identifier, ou seja, Identificador de Objeto Digital. É um padrão para identificação de documentos em redes de computadores, como a Internet. Este identificador, composto de números e letras, é atribuído ao objeto digital para que este seja unicamente identificado na Internet. 0 sistema oferece identificação univoca da propriedade intelectual de livros, artigos, periódicos e até imagens encontrados na Internet, associando a cada objeto seus dados básicos e sua origem.

O DOI foi desenvolvido recentemente pela Associação de Publicadores Americanos com a finalidade de autenticar a base administrativa de conteúdo digital. É concebido como um número, mas não tem um sistema de codificação pré-definido e também não traduz ou analisa esta numeração. O DOI atribui um número único e exclusivo a todo e qualquer material publicado. Este número de identificação da obra é composto por duas sequências: (1) um prefixo [ou raiz) que identifica o publicador do documento; (2) um sufixo determinado pelo responsável pela publicação do documento. $2,3,4,5,6$

0 prefixo/raiz DOI é nomeado pela IDF (International DOI Foundation], que garante que cada raiz é única. Os livros ou artigos publicados em periódicos, por exemplo, provavelmente utilizarão como sufixo o número que já consta do ISBN ou ISSN. Além de ser um mecanismo utilizado para garantir o pagamento de direitos autorais através de um sistema de distribuição de textos digitais, o DOI também é útil para auxiliar a localização e o acesso de materiais na web, facilitando a autenticação de documentos. Recentemente, os livros começaram a entrar nesse sistema, mas já existem cerca de três milhões de DOl's em uso, dando 
referências cruzadas e ativas sobre publicações acadêmicas e profissionais on-line $e^{2,3,6}$

No Brasil, a Plataforma Lattes do Conselho Nacional de Desenvolvimento Científico e Tecnológico [CNPq], por exemplo, utiliza o DOI como uma forma de certificação digital das produções bibliográficas regis- tradas pelos pesquisadores em seus Currículos Lattes.

(figura 1). Quando um programa navegador encontra um número DOI, utiliza o prefixo para encontrar o banco de dados da editora e ali acessa as informações relativas ao livro ou ao periódico, que podem incluir dados do catálogo, resenhas e links. ${ }^{7}$

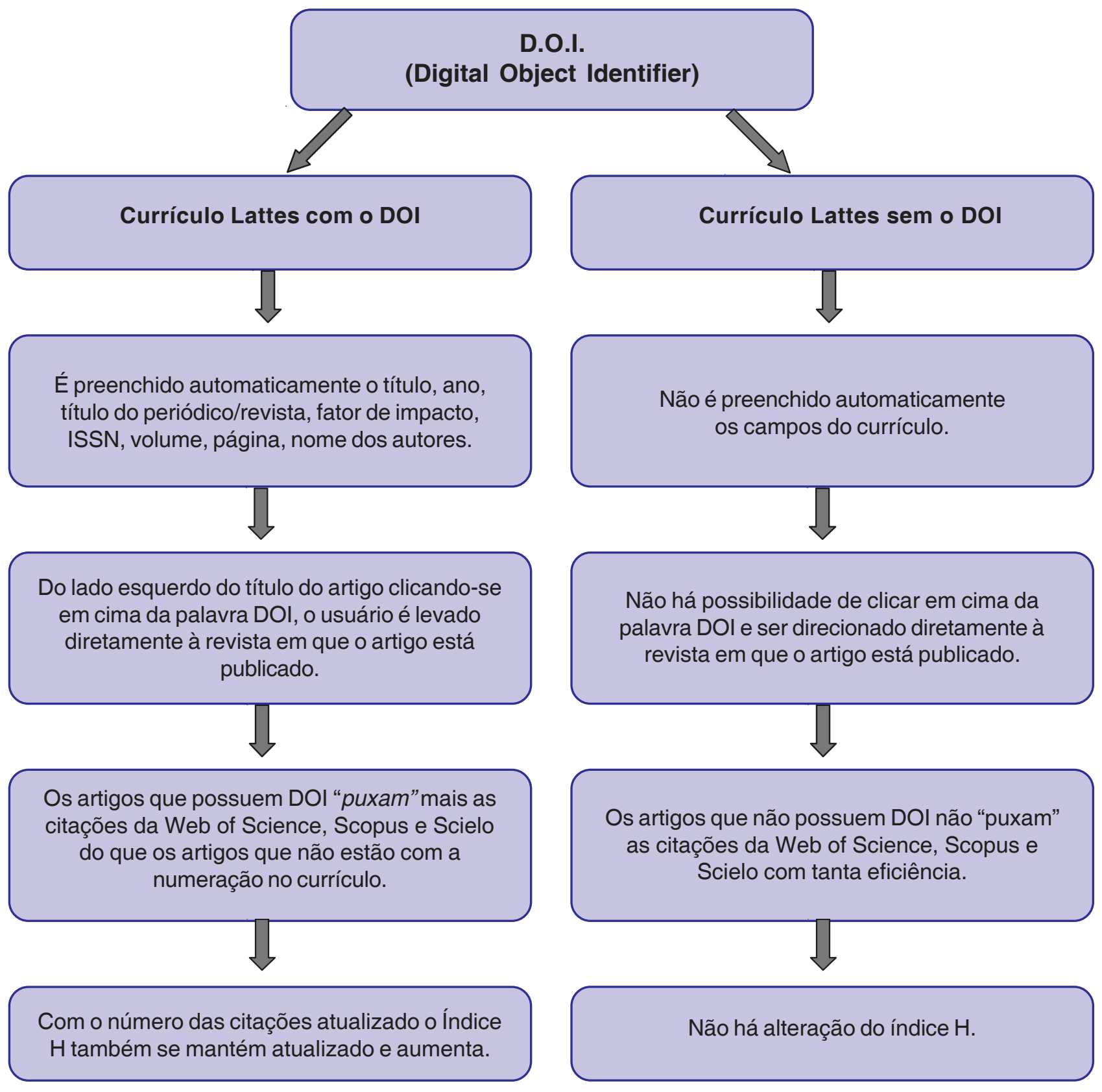

Figura 1: Estabelecimento de ligação entre o Currículo Lattes e o site do artigo publicado, nos casos de artigos que possuam o DOl. 
Sua aplicação mais frequente é para publicações em periódicos e obras com propriedade intelectual protegida (copyright), muitas delas associadas a bibliotecas virtuais. Através desse código é possivel estabelecer uma ligação entre o Currículo Lattes e o site do artigo publicado, caso exista o $\mathrm{DO}$, que preenche automaticamente vários campos. [ Figura 1].0 DOI é atribuído pela editora da publicação, e cabe a ela informar o número DOI de cada artigo. Se o seu artigo possui número DOI, provavelmente ele será informado no cabeçalho do artigo. Se o número DOl for considerado inválido, confira a validade no site http:// www.doi.org. $\underline{\underline{6}}$

Isto posto é com imensa satisfação que gostariamos de informar, por este editorial, que todos os artigos publicados na Revista Medicina ( Ribeirão Preto) terão seu DOI no cabeçalho da publicação, aumentando a visibilidade da publicação, com implicação direta no valor do índice $\mathrm{H}$ dos autores.

\section{Agradecimentos}

Agradecemos a Larissa B. Cossalter e Orlando M.C.C. Silva, pelas sugestões e apoio técnico.

\section{Referências}

1. Castro e Silva O, Silveira MRG. Revista Medicina, now published bimonthly. On the way to broader indexation: http:// revista.fmrp.usp.br/2014/vol47n2/editorial 47n2 2014.pdf [Acessado em 21/12/2014]

2. http://www.bibliotecas.usp.br [Acessado em 20/12/2014]

3. http://www.revistas.usp.br/rmrp [Acessado em 20/12/2014]

4. http://www.crossref.org/ [Acessado em 20/12/2014]

5. http://revista.fmrp.usp.br

6. http://www.doi.org. [Acessado em 20/12/2014]

7. http://pt.slideshare.net/carolineluvizotto/manual-de-preenchimento-do-currculo-lattes. [Acessado em 21/12/2014] 